\title{
Study on High-Cycle Fatigue Behaviors and Fracture Mechanism of RuT450
}

\author{
MengXiao Zhang ${ }^{1}$, JianChao Pang ${ }^{1}$, Meng Lingjian ${ }^{1}$, Li Shouxin ${ }^{1}$, Liu Qingyi ${ }^{2}$, Jiang \\ Ailong $^{2}$, and Zhefeng Zhang ${ }^{1}$ \\ ${ }^{1}$ Institute of Metal Research Chinese Academy of Sciences \\ ${ }^{2}$ Weichai Power Co., Ltd., Weifang 261061, PR China
}

December 31, 2020

\begin{abstract}
Fatigue failure is the most common failure mode of structural materials. In this study, the high-cycle fatigue properties at different temperatures, fracture surface morphologies and corresponding damage mechanisms of a widely used vermicular graphite cast iron RuT450 were investigated. It is found that the fatigue strength of RuT450 decreases with the increase of temperature, and the decreasing rate is affected by the change of morphology and content of graphite. In general, the cracks initiated from the graphite phase boundary and propagated through the pearlite lamellae. In addition, according to the change of matrix micro-structure and the slight change of graphite morphology at different temperatures, and combined with the change of crack propagation threshold value under different temperature conditions, a fatigue strength prediction method for vermicular graphite cast iron at different temperatures was proposed in this work, which has high prediction accuracy.
\end{abstract}

\section{Hosted file}

manuscript.pdf available at https://authorea.com/users/386415/articles/501812-study-on-highcycle-fatigue-behaviors-and-fracture-mechanism-of-rut 450 